\title{
A Interlocução de Narrativas: Um Estudo sobre Papéis de Gênero
}

\author{
Maria Helena Fávero \\ Inara Linn Maracci \\ Universidade de Brasília
}

\begin{abstract}
RESUMO - Retomamos a distinção entre sexo e gênero e entre papéis sexuais e de gênero na psicologia feminista. Referimos as contraposições à naturalização e discutimos a influência das ideologias da feminilidade e da masculinidade na socialização. Descrevemos um estudo sobre as concepções de quatro mulheres sobre os papéis de gênero, considerando a subjetividade na coleta e análise de dados. Utilizamos a narrativa e o grupo focal, tomando a proposição e os atos da fala como unidades de análise. Evidenciamos seis proposições articuladas a dois eixos principais: (a) as condições de vida e o abandono e (b) o significado e a prática da maternidade. Discutimos a identificação e o apego na socialização de gênero, defendendo o papel dos estudos psicológicos de gênero para as transformações sociais.
\end{abstract}

Palavras-chave: gênero, papéis de gênero, narrativa, grupo focal, feminismo.

\section{Narrative Interlocution: A Study on Gender Roles}

\begin{abstract}
In this article we resumed the distinction between sex and gender and between sex and gender roles in feminist psychology. We refer to antagonisms of naturalization and discuss the naturalization and we discuss the influence of femininity and masculinity ideologies on socialization. We describe a study on the conceptions of four women about gender roles, considering subjectivity in the data collection and analysis. Narrative and focus group are used, taking proposition and speech acts as units of analysis. We show six propositions connected to two main axes: living conditions and abandonment; the meaning and practice of motherhood. We discuss identification and attachment in gender socialization, advocating the role of psychological gender studies in social change.
\end{abstract}

Keywords: gender, gender roles, narrative, focus group, feminism

No final dos anos 1970, o American Psychologist publicou um texto de Unger (1979) - Toward a Redefinition of Sex and Gender - que se tornou um marco teórico de referência na defesa sobre a distinção entre o uso do termo sexo e o uso do termo gênero. Nesse trabalho, a autora afirma que "o termo gênero é introduzido em referência às características e traços socioculturais considerados apropriados para homens e mulheres" (Unger, 1979, p. 1085). Ela também salienta que "o uso diferencial do termo sexo supõe diferentes paradigmas para o exame das diferenças sexuais e a terminologia psicológica deveria refletir sobre essa distinção" (p. 1085). $\mathrm{O}$ artigo teve grande repercussão e é considerado como uma ferramenta conceitual particularmente importante para a distinção entre sexo e gênero, além de reter o seu valor heurístico até hoje (Pichevin \& Hurtig, 2007).

Quase uma década mais tarde, a abordagem etnometodológica proposta por West e Zimmerman (1987) - The doing gender - trouxe a tese segundo a qual o gênero é praticado no contexto das interações sociais. Assim, os autores contribuíram para que o termo gênero se firmasse para descrever o desempenho de atividades relacionadas aos papéis que assumimos em nossa prática do cotidiano pessoal, profissional e institucional.

A distinção entre sexo e gênero gerou a distinção entre papéis sexuais e papéis de gênero e esta distinção é particularmente importante para o trabalho que apresentamos aqui. Como Pichevin e Hurtig (2007) ressaltam:

1 Endereço para correspondência: Instituto de Psicologia, Universidade de Brasília, ICC Sul, Campus Darcy Ribeiro, Asa Norte, Brasília, DF, Brasil. CEP 70.910-900.E-mail: faveromhelena@gmail.com

O termo sexo não se refere somente à biologia ou à sexualidade. Ele também se refere aos corpos dos homens e das mulheres, o meio e o mediador das relações entre os sexos. Como François Héritier (1996) defendeu em sua análise, a primeira diferença observável entre os homens e as mulheres é a diferença entre seus corpos e essas diferenças geram um valor diferencial para cada sexo. Representações da procriação, dos respectivos papéis de mãe e de pai, dos fluidos produzidos pelo corpo (tais como leite, sêmen, e assim por diante) são enraizados na leitura social do sexo biológico. A relevância da distinção sexo/ gênero tem sido reafirmada pela pesquisa em várias áreas. (p. 450 , tradução nossa)

$\mathrm{Na}$ análise de Rutherford (2011), a distinção entre sexo e gênero gerou uma discussão decisiva na própria psicologia feminista, contexto no qual Unger (1981) teve, mais uma vez, um papel fundamental ao enfatizar que as abordagens metodológicas necessariamente supõem abordagens conceituais. Em outros termos, ela estava se referindo à relação inevitável entre as concepções teóricoconceituais e a prática metodológica na pesquisa (ver Fávero, 2010). Assim, Unger (1981) e outras pesquisadoras, como Morawiski (1997), passaram a analisar e discutir o papel dos entraves - entre os quais as chamadas políticas do conhecimento - para a geração de transformações em todas as áreas de conhecimento, em defesa da psicologia reflexiva. Em suma, instalou-se uma demanda em termos da necessidade de reflexão crítica sobre a relação entre o aporte teórico conceitual e a proposta metodológica (Fávero, 2015).

Desse modo, o termo papéis sexuais foi substituído, gradativamente, pelo termo papéis de gênero nos estudos 
psicológicos, embora, como lembre Michèle Ferrand em uma entrevista a Rial, Souza Lago e Grossi (2005), já houvesse sido introduzida a abordagem das chamadas relações sociais de sexo, tanto nas pesquisas empíricas como nas reflexões teóricas, como um modo de se contrapor à concepção que defendia a chamada essência ou constância feminina. O contraponto pretendia, portanto, evidenciar que, ao contrário da tese da naturalização segundo a qual as mulheres desempenhavam determinados papéis porque lhes era próprio e natural, as mulheres constituíam um grupo social "sobrecarregado com certo tipo de tarefas, designadas pela divisão social e sexual do trabalho: donde a necessidade de mostrar seu aspecto histórico e social (portanto, arbitrário e reversível)" (Rial et al., 2005, p. 679). O termo gênero passa a ser tomado, portanto, como uma categoria de análise histórica e definido como um elemento constitutivo das relações sociais baseadas nas diferenças percebidas entre os sexos e como um modo fundamental de significar as relações de poder (Scott, 1988).

Compatível com essa abordagem, Fávero (2010) considera os papéis de gênero para designar a vinculação entre a categoria gênero e as influências sociais e culturais que fundamentam a adoção pessoal de determinados papéis, expressos no desempenho cotidiano de tarefas, tal como a divisão de tarefas, por exemplo. Essa autora defende a necessidade da tomada de consciência dessa vinculação do ponto de vista da socialização, entendida como um processo do desenvolvimento psicológico, assim como da tomada de consciência da influência das ideologias da feminilidade e da masculinidade nesse processo.

Essa proposta é, portanto, consonante com a ênfase da abordagem feminista deste século XXI em termos da necessidade de promoção de mudanças. Isso porque tira do parêntese a ideia já referida de Michèle Ferrand (conforme citada por Rial et al., 2005) a respeito da arbitrariedade e da reversibilidade da divisão de trabalho baseada nos papéis de gênero, para torná-la parte dos três componentes básicos da perspectiva metodológica feminista, a saber: a atenção à reflexividade; a formulação de métodos compatíveis com o objeto de estudo; a orientação para a mudança social.

Em suma, trata-se de defender a consideração da psicobiografia, da sociocultura e das transformações nos estudos psicológicos de gênero, como proposto por Fávero (2010), o que, como ela afirma, implica a "busca de um sujeito inteiro e não dividido pelas dicotomias mente e corpo, pensamento e linguagem, razão e emoção", partindo "da análise das próprias concepções sobre o conhecimento científico" e trazendo-a "para dentro da Psicologia, o que é fundamental para que se mantenha a defesa de que se há construção, então, é possível se reconstruir, tendo em vista as mudanças pessoais, institucionais e socioculturais" (Fávero, 2010, p. 14, itálico da autora).

$\mathrm{O}$ estudo que descrevemos aqui se inspirou nessa discussão epistemológica e na tese segundo a qual "o desenvolvimento psicológico humano se dá na interação entre os aspectos subjetivos, desenvolvimentais e cognitivos dos processos semióticos num contexto psicológico e o fundamento histórico, institucional e ideológico dos sistemas de signos num contexto sociocultural" (Fávero, 2005, p. 17). Levando em conta essa tese, nosso estudo se centrou na concepção de mulheres sobre os papéis de gênero e assumiu o desafio da pesquisa metodológica para considerar a subjetividade - tomada no sentido discutido por Morawiski (2005), Gergen (2006), Smith (2005), Richards (2002) e Smedslund $(2009,2012)$ - tanto na coleta de dados, como na construção da análise de dados.

Para isso, retomamos a proposta de Fávero $(2010,2012)$ em seus dois aspectos teórico-metodológicos: em primeiro lugar, sua defesa, em consonância com Barthes (1977), Bruner (1991) e Ricoeur (1991), da narrativa bibliográfica como uma produção pessoal que espelha a interação dialética do sujeito humano psicologicamente ativo e da dinâmica sociocultural, compatível, portanto, com a perspectiva de Chase (2008) e com os autores referidos no parágrafo anterior. Trata-se, como defendido por Gergen (1990, 2001), de considerar ambos: a narrativa como um texto e como um instrumento da mente na construção da realidade. Em segundo lugar, a defesa de Fávero $(2010,2012)$ no que diz respeito à utilização do grupo focal - tomado como instância interativa para a discussão das proposições gerais obtidas nas narrativas individuais - e no que se refere aos atos da fala, que são considerados como unidade de análise das trocas verbais, tal como explícito no trabalho de Fávero e Abrão (2006) e retomado por Costa (2006), Oliveira Vieira (2008) e Abrão (2009).

Na sua proposta de utilização do grupo focal, Fávero (2012) considera dois aspectos particulares da proposta de Vion (2000): o conceito de espaço interativo e o próprio conceito de interação, tomado como uma instância mais ampla e inserido em uma história interacional. Portanto, para Fávero (2012), trata-se de criar um espaço interativo particular e analisar as interlocuções geradas nesse espaço, tomando-as como atos da fala em consonância com o conceito de inter-ação, isto é, como um ato através do qual os atores sociais interagem. Neste trabalho, relatamos uma articulação metodológica entre narrativas e grupo focal, de modo que o objeto de discussão deste se origina das próprias narrativas das participantes.

\section{Método}

Assumindo a articulação teórica e metodológica já referida e após a aprovação do Comitê de Ética em Pesquisa do Instituto de Ciências Humanas da Universidade de Brasília, obtivemos a adesão de quatro mulheres brasileiras - ficticiamente chamadas de Ana, Beatriz, Clara e Dalva -, que aceitaram participar das três fases consecutivas de nosso estudo, em que cada fase é fundamentada na análise da fase anterior. As quatro exerciam funções administrativas em uma universidade da região centro-oeste e se situavam na faixa etária entre 37 e 55 anos, sendo que três delas tinham escolaridade de nível superior e uma, de nível médio. Todas eram mães. Quanto à situação civil, uma era casada, uma era solteira, uma era divorciada e uma delas era separada de seu cônjuge.

$\mathrm{Na}$ primeira fase, propusemos às participantes a elaboração escrita de uma narrativa: "Minha estória de vida: de menina até hoje". Tomamos cada narrativa como um texto, no sentido semiótico de Lotman $(1988,1990)$ e analisamos 
seu conteúdo através das suas proposições tomadas no sentido backtiniano, o que significa:

Converter este conteúdo em proposições, isto é extrair os sentidos de uma forma linguística mais complexa - o parágrafo, o período - através de uma forma linguística mais simples, a frase afirmativa. (...) Seguindo esta linha de raciocínio, a proposição é o resultado da articulação do sentido, tomado na sua forma menos complexa e mais explícita, com a estrutura linguística, tomada na sua forma menos complexa e mais explícita. Portanto, assumindo a abordagem da semiótica da cultura, podemos eleger a proposição como uma unidade de análise. (Fávero \& Trajano, 1998, pp. 230-231)

Esse procedimento de análise nos permitiu evidenciar as concepções consensuais sobre os papéis de gênero e, ao mesmo tempo, permitiu-nos evidenciar as particularidades das narrativas de cada uma das participantes. Assim, por exemplo, considerando o trecho da narrativa: "Casei em 1980, fui feliz vários anos de minha nova vida. Tive filhos, três, depois fui amadurecendo com a própria vida, querendo sempre ter o meu espaço"; é possível obter-se as seguintes proposições: (a) Casei e fui feliz em minha nova vida; (b) Tive três filhos; (c) Depois dos filhos, amadureci com a própria vida; (d) O meu amadurecimento me fez desejar o meu próprio espaço.

A segunda fase da coleta de dados foi constituída pela apresentação, a cada participante, de um conjunto de questões sobre a análise de suas narrativas, de modo que, nessa fase, cada uma poderia esclarecer aspectos da primeira fase e corrigir nossa análise. O número de perguntas variou de 7 a 15, dependendo da extensão da narrativa produzida na primeira fase. Para exemplificar essa segunda fase, temos dois exemplos de perguntas: (a) Você narra que: "Minhas primas tinham muita inveja... passei por muitas humilhações". Por que elas tinham inveja? Inveja de quê? A que tipo de humilhação você se refere? (b) Seria possível nos dizer o que veio a sua cabeça ao responder a estas questões? Sobre o que está refletindo nesse momento?

Agendaram-se horários diferentes para cada uma, de modo que, após a apresentação das questões digitadas em folha A4 e após o repasse das instruções sobre o uso de um gravador, elas permaneciam em ambiente privado e sem restrição de tempo para gravar suas respostas. As respostas registradas foram transcritas na íntegra e seu conteúdo foi analisado de acordo com o mesmo procedimento utilizado para a análise das narrativas.

$\mathrm{Na}$ terceira fase da coleta de dados - constituída pelo desenvolvimento de três sessões de grupo focal -, propusemos às participantes a discussão, em grupo, sobre os aspectos comuns que se evidenciaram na primeira e na segunda fase da coleta de dados. Essas sessões de grupo focal foram transcritas na íntegra e analisadas considerando-se as interlocuções produzidas na situação interacional como atos da fala, tomados como unidade de análise. Esse procedimento permitiu sua categorização, nas cinco esferas, como reelaboradas por Fávero $(2007,2012)$, a partir da proposta de Chabrol e Bromberg (1999), quais sejam:

1) de informação (todo ato da fala que visa descrever, categorizar, definir, considerar os objetos do mundo e sua relação de maneira não avaliativa); 2) de avaliação (todo ato da fala que exprime um julgamento de valor, ou uma apreciação);
3) de interação (todo ato da fala que visa à coelaboração das identidades dos parceiros e a cogestão das suas relações); 4) acional (todo ato da fala que propõe o fazer, que incita e exorta o fazer, o engajamento); 5) contratual (todo ato da fala que tem por função gerar ou regular a comunicação, em função dos objetivos, dos jogos de ações e do contrato de comunicação). (Fávero, 2012, p. 107)

Portanto, nessa terceira fase da coleta de dados, tratavase, como no estudo de Fávero e Abrão (2006), “de explicitar as funções e significados da produção resultante de trocas verbais em grupo e não do discurso individual" (p. 178). A segunda e terceira fases do estudo foram registradas em áudio e transcritas para a análise de acordo com o modelo internacional para transcrição proposto por Tian, Jimarkon e Singhasiri (2000).

\section{Resultados e Discussão}

A análise das narrativas, realizada na primeira fase da coleta de dados já descrita, evidenciou seis aspectos comuns: (a) a referência à ausência do pai e do pai dos seus filhos; (b) o foco predominante na queixa sobre o abandono do pai e a minimização do apoio familiar recebido para se desenvolverem como pessoas e profissionais; (c) a queixa sobre o papel de provedoras; (d) o foco predominante na ausência do apoio masculino para prover a família; (e) o foco predominante no papel de mãe, em detrimento de outros papéis; (f) a escassa atribuição de valor a si mesmas como pessoas e como profissionais.

Esses seis aspectos se apresentaram articulados a dois eixos principais. O primeiro eixo diz respeito ao foco na queixa sobre as condições de vida, relatada com ênfase nos aspectos negativos centrados em referência ao sofrimento causado pelo abandono dos homens - seus pais e os pais de seus filhos. A elaboração comum que sustenta esse foco mantém dois movimentos sincronizados: minimizam tanto o apoio feminino recebido para se desenvolverem como pessoas e como profissionais, assim como minimizam esse mesmo desenvolvimento e, ao mesmo tempo, maximizam a ausência do apoio masculino. $\mathrm{O}$ foco na queixa é mantido nas narrativas mesmo quando as participantes se referem à sua estabilidade profissional e financeira, estabilidade esta que lhes permite assumir efetivamente o papel de provedoras e pessoas responsáveis socialmente do ponto de vista do cuidado com a família.

O segundo eixo diz respeito ao desempenho do papel de mãe, referido como aquele compatível com a concepção do mito do amor materno, isto é, um amor incondicional, visto como natural e inato e responsável por todos os atos dos filhos, independentemente de suas idades. O sentido atribuído a esse papel é o de um fardo e, ao mesmo tempo, central nas suas vidas, minimizando os papéis referentes à pessoa, à mulher e à profissional como se estes se incompatibilizassem com o papel de mãe.

Compatível com esses dois eixos, a análise das narrativas evidenciou uma concepção de felicidade que depende necessariamente do outro e que é permeada pelo sentimento de apego, no sentido analisado por Chodorow $(1979,1999$, 2002a, 2002b), Brody (2000) e Fávero (1999, 2010). Esse 
apego se explicita de vários modos: no desejo de encontrar o verdadeiro amor, no desejo de ter o marido junto a si e aos filhos e na tentativa de resgatar o pai através do próprio marido.

Assim, a análise das narrativas evidenciou a presença dos valores da ideologia patriarcal na concepção dos papéis femininos e masculinos, assim como o vínculo entre a queixa sobre a ausência de apoio masculino e a ausência do sujeito masculino no papel de provedor. Esses dados são compatíveis com diferentes estudos como, por exemplo, o de Costa (2006) sobre o conceito de envelhecimento, o de Abrão (2009) sobre a análise psicológica do relato de mulheres brasileiras que participam da política, o de Vespa (2009) sobre a análise interseccional sobre o curso de vida e o de Robinson (2012) sobre a relação entre sexualidade, infância e conhecimento.

Essa ideologia patriarcal também se fez presente nas narrativas das participantes através das referências às suas mães, tidas como submissas à autoridade dos maridos e silenciosas diante da postura dos homens, referidos, por sua vez, como pessoas autoritárias, ativas e detentoras do comando e poder de suas famílias. Desse modo, evidenciamos uma narrativa contraditória, visto que um dos eixos predominantes e comuns é justamente a ausência do pai e, portanto, do patriarca que comanda: ele é ausente e comanda.

$\mathrm{Na}$ segunda fase de coleta de dados, apresentamos essa nossa análise às participantes e as questionamos, individualmente, sobre a sua pertinência, conforme o procedimento já descrito. A análise das respostas a tal questionamento evidenciou a concordância das participantes com a análise apresentada sobre as narrativas, reafirmando os seis temas relacionados aos dois eixos já referidos por meio de subtemas a eles relacionados e o acréscimo de mais dois: um deles referido pelas participantes como a tomada consciência sobre si mesma durante esta segunda fase do estudo e o outro relacionado à adesão, no sentido de que o procedimento utilizado na coleta de dados havia favorecido a tomada de consciência referida e daí a adesão. Os sete temas foram: (a) a dependência dos outros; (b) a visão a respeito da própria mãe; (c) o apoio familiar e o papel da mãe; (d) ter sido e permanecer controlada; (e) ser a mantenedora da família; (f) a tomada de consciência de si mesma; (g) a adesão à análise dos dados no nosso estudo. Tais dados não apenas evidenciaram a partilha de tradições de linguagem e de sentidos historicamente construídos (Gergen, 2006) como também confirmaram, por isso mesmo, o aspecto dialógico da interação das participantes e dos dados da análise das suas próprias narrativas.

Assim, o primeiro tema - a dependência do outros apareceu vinculado à ideia da necessidade de incentivo para a realização de projetos pessoais, referido como dependência e tratado como negativo: "Olha só como eu estou dependente! De alguém, pra falar alguma coisa que eu tenho que fazer. Eu me vejo nisso, todo o momento da minha vida", gravou Dalva na segunda fase do estudo.

O segundo e terceiro temas se relacionam estreitamente - o apoio familiar e o papel da mãe e a visão a respeito da própria mãe-, em que elas reconhecem o apoio de irmãs mais velhas (o que não fora explicitado nas narrativas) e em que atribuem à mãe o papel de controladora do comportamento e da virtude moral das filhas, referida de duas maneiras: como submissa calada e como submissa autoritária. O que prevalece em ambos os casos é o tom de censura: "ela é um pouco contraditória. Às vezes é tão autoritária com algumas coisas, mas assim muito submissa com outras", registrou Ana.

O quarto tema - ter sido e permanecer controlada reafirma o discurso das narrativas sobre o ter tido uma infância controlada pela família e expande tal controle para o presente: "Bem hoje eu me sinto ainda assim muito controlada, inclusive pelos meus pais apesar de não morar com eles né? E controlada pelo meu marido, controlada pelas minhas filhas, não sei assim exatamente como, de como isso funciona, como vem isso né?", registrou Beatriz, por exemplo.

O quinto tema - ser a mantenedora da família - vinculase à ideia de ser obrigada a priorizar os gastos com a família em detrimento de si mesma, mantendo um tom de censura pelo abandono ou pelo investimento financeiro que o marido ou companheiro fez, ou faz, em atividades consideradas não prioritárias. O sentido da queixa é duplo: refere-se à falta de diálogo sobre o referido investimento e, ao mesmo tempo, a uma autocensura em reação ao próprio conformismo diante dessa realidade.

A tomada de consciência de si mesma, sexto tema, parece ser uma recusa ao conformismo referido antes e expandido a todas as situações: "E eu sempre tive, eu acho que, não sei o que, que me levava a ter paciência? Não sei essa coisa de aceitar tudo né? E talvez hoje, olhando mais prá mim, me vendo mais crua e nua, olhando mais o que... que tá sobrando de tudo que eu já fui e que eu sou, ahn! Talvez fique mais difícil lidar com essa coisa de suportando tudo de todos", registrou Ana.

A adesão à análise dos dados no nosso estudo, sétimo tema, evidenciou, nessa segunda fase do estudo, o interesse na participação e a disponibilidade para uma nova fase de coleta de dados, sinalizando a adesão a uma situação de reflexão consigo mesmas como evidenciado nas perguntas que fazem a si próprias, como é o caso do extrato referido no parágrafo anterior. Vale a pena lembrar que Ana estava sozinha registrando suas respostas em áudio quando dialoga com as questões propostas sobre sua narrativa (primeira fase do estudo) e consigo mesma.

Considerando a análise de Chodorow (1979, 1999, 2002a, 2002b) tal como retomada por Fávero (2010) para discutir a socialização gendrada e a ideologia da masculinidade e da feminilidade, podemos dizer que os dados obtidos nessas duas fases do estudo revelam uma concepção de exigência das participantes consigo mesmas, traduzida na referência à paciência, ao cuidado e à aceitação incondicional dos outros. Ao mesmo tempo essa exigência e o empenho em cumpri-la parecem engendrar uma demanda de apoio, apego e aprovação, que se apresenta, por sua vez, na forma de exigência e cobrança em relação aos outros.

Com base nesses dados, algumas questões podem ser formuladas para o desenvolvimento de estudos futuros: A socialização segundo a ideologia da feminilidade, centrada no apego e na dependência e, portanto, na constante necessidade de agradar, engendraria uma exigência excessiva das meninas, das adolescentes e das mulheres consigo mesmas? Essa exigência excessiva tenderia a se expandir e abarcar os 
outros a sua volta? Seria este o significado da censura que perpassa os dados obtidos junto às participantes deste estudo, tanto em relação ao outro, como em relação a si próprias? Estaria esse significado presente em narrativas de meninos, de adolescentes e de homens? Esse significado estaria presente nas narrativas de mulheres e de homens homossexuais?

A terceira fase da coleta de dados - o desenvolvimento de três sessões de grupo focal - centrou-se na discussão em grupo dos sete temas mencionados anteriormente e referentes à primeira e à segunda fases da coleta de dados. Elaboramos 12 slides em Power Point. digitados em fonte Calibri 28, em caixa alta. Como exemplo, apresentamos em anexo a reprodução dos slides 1 e 2. Cada slide permanecia projetado durante a sua discussão. A série de slides foi finalizada na terceira sessão de grupo, sendo que cada uma teve duração aproximada de 50 minutos.

Portanto, nesta terceira fase, propôs-se uma situação interativa na qual o foco de análise, como referido antes, foram os atos da fala tomados como unidade de análise das interlocuções ali produzidas (Fávero, 2012). Desse modo, para a análise da transcrição das sessões de grupo focal, procedemos à elaboração de tabelas constituídas de quatro colunas, que, como no exemplo apresentado por meio da tabela 1, identificam o trecho da transcrição, transcrevem $\mathrm{o}$ ato da fala, identificam a esfera no qual se situa o ato e categorizam-no.

A análise dos atos da fala apontou para uma predominância de interlocuções nas esferas de informação, avaliação e interação através das seguintes categorias de atos da fala: informar, explicitar e confirmar na esfera da informação; de avaliar e validar na esfera da avaliação; e de complementar e conformar na esfera da interação. Isso sugere um pacto entre as participantes na defesa de significados e de pontos de vista comuns. Assim, as categorias de atos da fala que visam retificar, contestar, infirmar e invalidar apareceram muito pouco, evidenciando que prevaleceu, nas sessões de grupo focal, um ambiente de conformidade e de apoio mútuo entre as participantes.

Esses dados podem sugerir, de um lado, uma concordância com as análises de Câmara e Carlotto (2007), Mehta e

Tabela 1 Extratos de Transcrição dos Atos da Fala da Primeira Sessão do Grupo Focal

\begin{tabular}{clcl}
\hline Trecho & Transcrição dos Atos da Fala & $\begin{array}{l}\text { Esferas dos } \\
\text { Atos da Fala }\end{array}$ & $\begin{array}{c}\text { Categorias dos } \\
\text { Atos da Fala }\end{array}$ \\
\hline 1. & $\begin{array}{l}\text { E: }\{\text { A pesquisadora passa a ler os slides do Power point para as participantes\}. "Minha } \\
\text { história de Vida: de menina até hoje, discussão em grupo focal dos principais dados } \\
\text { colhidos nas narrativas. Vocês estiveram lidando com as narrativas das suas vidas }\end{array}$ & Contratual & $\begin{array}{l}\text { Estabelecer } \\
\text { contrato }\end{array}$ \\
& Acional & Propor &
\end{tabular}
aqui em duas ocasiões: na primeira escreveram um texto e na segunda responderam as questões suscitadas no texto" \{quando vocês gravaram né?\} "Hoje convidamos vocês a discutirem juntas: 1) O que estes dois momentos focados nas suas vidas levaram vocês a pensar, refletir e sentir?".

2. <Ana: Eu acho que quando a gente para pra falar da gente é um momento assim de... um conhecimento mais profundo que o dia a dia da gente é tão corrido, filho, família, casa, trabalho e a gente não para pra pensar um pouco. Então pra mim foi um momento assim de REFLEXÃO: pra onde eu vou de onde eu vim o que, que eu quero? É uma chacoalhada na minha vida.

3. <Beatriz: A gente vê, assim, coisas que a gente nunca imaginou, assim, coisas que já passou da infância, da adolescência, a gente fala: Nossa! Eu com a cabeça de hoje faria tão diferente do que naquela época, né? A gente pensa assim, e como ela falou a gente reflete muito sobre a vida mesmo de coisas que já passou, o que vem pra frente também diante do que a gente vai revendo, é muito bom>

4. Clara: Não. É como ela falou. O autoconhecimento né? Porque a gente, para a gente vai vivendo, vai vivendo e vai levando a vida e você não para assim pra pensar, exatamente o que ela colocou. O que? Que eu quero? QUEM SOU EU DE VERDADE? As pessoas tem uma imagem de você e às vezes você se olha por aquela IMAGEM que as pessoa TEM E NÃO POR AQUILO QUE VOCÊ MESMO TEM QUE VOCÊ SE VÊ NO ESPELHO E O QUE VOCÊ SENTE NÉ? Você vive mais pelo reflexo, mas é o reflexo dos outros, mas ah! Muda o cabelo... Ah, faz isso, você vai mudando né? É uma opinião daqui, uma opinião do outro lado e que você às vezes nem se pergunta, mas é isso mesmo que eu quero?...eu quero mudar o meu cabelo? Muitas vezes a gente nem QUER, A GENTE SÓ FAZ AQUILO QUE OS OUTROS ESTÃO QUERENDO QUE VOCÊ FAÇA.

5. Ana: Bom vamo COLOCAR NO PAPEL? O que, que eu fiz, eu nunca fiz esse trabalho, esse exercício de reflexão, pra onde eu quero ir né? ÀS VEZES É O MOMENTO DA GENTE DAR UM TEMPO PRA GENTE RESOLVER... A nossa vida, porque a gente não sei se é cultural? Pra mim eu vejo isso. É você tá mais em função DOS OUTROS DO QUE DE VOCÊ MESMO. Então você tem que ter um tempo pra você, eu tô aprendendo muito agora, TÕ ME COBRANDO MAIS. Resolva a sua vida, cuide da sua vida, faça você, FAÇA... O SEU MUNDO porque as coisas fluem, né?

$\begin{array}{ll}\text { Avaliação } & \text { Avaliar } \\ \text { Informação } & \text { Exemplificar }\end{array}$

Avaliação Avaliar

$\begin{array}{ll}\text { Avaliação } & \text { Avaliar } \\ \text { Informação } & \text { Exemplificar }\end{array}$


Strough (2010) e Rosistolato (2009) em referência a uma suposta necessidade de filiação e de busca de apoio de pares. Por outro lado, eles podem evidenciar a recusa deliberada de uma opinião divergente, o que é diferente dos dados obtidos no estudo de Fávero e Abrão (2006) sobre a discussão de adolescentes diante de cenas de telenovela, na qual as adolescentes mais velhas evitavam confrontar a divergência da opinião dos adolescentes, mudando o foco da discussão:

À medida que a idade avança há uma maior integração entre os subgrupos masculinos e femininos durante a discussão, integração esta, podemos dizer, promovida pelos sujeitos femininos: nos grupos constituídos de sujeitos mais velhos, os do sexo feminino evitam contestar os masculinos, sobretudo no que se refere à conduta moral da personagem da cena: ou avaliam negativamente a conduta da personagem e são apoiadas pelos sujeitos do sexo masculino, ou enveredam por considerações, como foi o caso do último grupo discutido, no qual se tomou distância da cena em si e se enveredou para a discussão do papel social da telenovela. Desse modo, a discussão torna-se impessoal e este seja, talvez, um recurso ao não afrontamento. (Fávero \& Abrão, 2006, p. 180)

No estudo que aqui relatamos, além desse desvio de foco da discussão, há o afrontamento de opiniões divergentes e a evidência de sua desconsideração através de um tipo de desqualificação e descrédito que recorre até à ironia, como na sequência a seguir:

Beatriz: Lá em casa é diferente @. Lá em casa eu tô em primeiro lugar. Atualmente, né? Já foi mais assim né... A terapia que me ajudou...

Dalva: Aonde você fez terapia? Eu quero ir nessa terapia sua @@.

Beatriz: Eu atualmente lá em casa tô em primeiro lugar.

Ana: E você é tratada com tal e respeitada?>

Beatriz: Respeitada. Que eu não tenho marido, né? Sou eu e eu só tô com dois né? (...) eu me coloco em primeiro lugar em tudo. Inclusive eu tô botando na cabeça deles que eu quero que eles saiam de casa. Que eles vão morar só... o que eu quero, eu quero ter a minha vida.

Trata-se, como na análise de Burns (1999), de um exemplo no qual se expressa a relação de poder entre mulheres, tema pouco abordado nas pesquisas. Esses resultados sugerem questões para estudos futuros, relacionadas à natureza da diferença das práticas femininas e das masculinas na lida com posições divergentes. Isto é, posições divergentes entre homens, entre mulheres e entre homens e mulheres - o que certamente tem implicações para as interações pessoais, tanto no âmbito da vida pessoal como no profissional.

É interessante notar que a posição alternativa colocada por Beatriz afronta justamente a principal queixa do grupo, isto é, a hierarquia que as coloca sempre em um lugar sem privilégio, pois antes era o modelo patriarcal tradicional com o pai no centro e agora é o modelo no qual os filhos estão no centro, como na sequência:

Ana: Indivíduo da casa, a mãe e depois os filhos. Hoje não. Tem os filhos, o pai e a mãe em terceiro lugar. Então é... e a gente com essa situação é às vezes pra entender isso foi muito dificil. Porque agora é o filho, ofilho em primeiro lugar, o que domina... uma casa.

Dalva: Porque a vida gira em torno dele@>>
Ana: É. Ai vem o pai e depois a mãe que fica em terceiro ainda. Porque a mãe cede tudo, né?.

A análise dos atos da fala das sessões de grupo focal, como em outros estudos (e.g. Costa, 2006; Oliveira Vieira, 2008), também revelou que o espaço interativo promove a tomada de consciência e que essa promoção está vinculada, sobretudo, a um dos participantes, cujos atos da fala instigam novas reflexões. Assim, a discussão sobre a questão relacionada à posição subalterna da mulher, no modelo familiar contemporâneo, e ao papel materno trouxe ao grupo, por meio de uma das participantes, uma tomada de consciência de que poderia haver uma análise alternativa sobre a aceitação desse papel: a sua relação com a possibilidade de controle das relações interpessoais familiares.

Esse é um aspecto interessante dos resultados obtidos neste estudo, seja do ponto de vista teórico conceitual, seja do ponto de vista metodológico. Primeiro porque tais resultados corroboram as análises históricas e psicológicas desenvolvidas nos anos 1990 (Algranti, 1993; Del Priori, 1993; Perrot, 1998; Rocha-Coutinho, 1994) sobre o poder feminino na família. Em segundo lugar, porque evidenciam que é possível, através do pensamento reflexivo engendrado pela tomada de consciência, vista no sentido desenvolvimental piagetiano e vygotskyniano, elaboraremse novos significados sobre os papéis de gênero. $\mathrm{O}$ extrato abaixo é um exemplo:

Ana: Isso é ser dominadora entendeu? E ainda vinha gente dizer assim: Nossa, mas você é demais, hein? Tinha vezes que dizia: Nossa! Mas você consegue fazer isso e aquilo, então aquilo me... Quanto mais falava, mais eu fazia. Minha sogra falava: Nossa! O V. casou com a pessoa certa. E ai quanto mais falava, mais eu fazia. Gente! Pra que?. (...) Eu acho que quando a gente para pra falar da gente é um momento assim de... um conhecimento mais profundo que o dia a dia da gente é tão corrido, filho, família, casa, trabalho e a gente não para pra pensar um pouco. Então pra mim foi um momento assim de reflexão: pra onde eu vou? De onde eu vim o que, que eu quero? É uma chacoalhada na minha vida.

Clara: Não. É como ela falou. O autoconhecimento né? Porque a gente, para a gente vai vivendo, vai vivendo e vai levando a vida e você não para assim pra pensar, exatamente, o que que eu quero? Quem sou eu de verdade?... A gente só faz aquilo que os outros estão querendo que você faça.

A tomada de consciência e a reelaboração também se evidenciaram em relação à queixa que predominou nas fases um e dois deste estudo: a falta de apoio no passado e no presente, sobretudo em referência ao abandono do pai dos seus filhos ou em referência a um marido sempre ausente e ao fardo da maternidade. Assim, tanto o papel de suas famílias como também o papel do marido é retomado e reavaliado pelas participantes, como se evidencia na voz de Dalva: "Interessante que isso faz a gente refletir né? Agora mesmo eu tô aqui pensando, por exemplo, com essa empreitada do meu mestrado, a pessoa que mais tá me apoiando é o ausente do meu marido!".

Outro resultado a ser ressaltado emerge da discussão sobre a maternidade e sobre o amor materno, tomado como instintivo, natural e incondicional, tal como já dito em relação aos dados obtidos na primeira e na segunda fase do estudo, no mesmo sentido discutido histórica e filosoficamente por 
Badinter (1985). O tema é retomado nas sessões de grupo focal: "Mãe é mãe; mãe nenhuma larga um filho". "O homem larga filho, mas mãe, não". "Os filhos são sempre da mãe", defende Dalva. A exigência desse papel e desse amor inquestionável é claramente trazida para a discussão, como na voz de Ana: "Tô vendo isso. E como é dificil a gente reeducar ou a gente tentar aprender pra como lidar com essa situação! É difícil. Eu fico desesperada, igual a você! Meu deus! Será que eu estou renegando a minha filha, será que eu... ah! Eu vou congelar?".

Relacionado ao tema da maternidade e aos temas anteriores, já referidos, as participantes discutiram suas práticas pessoais nas interações familiares. A discussão evidenciou que, entre os papéis femininos, o papel de mãe e cuidadora é central, tal como no estudo desenvolvido por Bordini e Sperb (2012).

No entanto, os resultados de nosso estudo vão adiante. A análise dos atos da fala nos grupos focais evidencia um consenso que revela uma tomada de consciência por parte das participantes sobre suas contradições e sobre o seu próprio papel na manutenção de determinadas práticas relacionadas ao cuidado dos filhos e da família. Esse consenso pode ser enunciado através de três proposições: (a) As mulheres tendem a assumir todas as tarefas cotidianas relacionadas ao cuidado dos filhos e da família, desqualificam as tentativas de participação dos homens e, ao mesmo tempo, reclamam de sua não participação; (b) As mulheres esperam a participação dos outros nessas tarefas cotidianas sem explicitar sua demanda e queixam-se silenciosamente; (c) As mulheres respondem ao papel de serem sempre eficientes, tal como esperado pelo meio sociocultural e, ao mesmo tempo, procuram se manter dóceis.

\section{Considerações Finais}

Os dados aqui apresentados e discutidos colocam em evidência a tese segundo a qual o aspecto central da socialização de gênero das meninas está na identificação e no apego, enquanto a do menino se centra na separação e na individuação, tal como proposto por Chodorow (2002a) e retomado por Fávero (2010). Por implicação, a autoestima das meninas, das adolescentes e das mulheres fundamenta-se, sobretudo, em suas relações com os outros, o que pode tornálas uma presa fácil do chamado sentimento de inadequação e de vergonha e, portanto, uma presa fácil da intimidação, o que completa o círculo, reafirmando o poder do outro (ver Fávero, 2010). É com base na natureza dessa socialização que essa autora defende, como Leaper (2000), por exemplo, a necessidade de se considerar, no estudo do desenvolvimento psicológico humano, as estruturas patriarcais que engendram a natureza dos microssistemas de interação de crianças, de adultos e de ambos. Para fundamentar sua posição, Fávero (2010) salienta dois aspectos particulares para os quais a consideração desse tipo de estudo pode trazer fundamento: a promoção de mudanças nas concepções de papéis de gênero e a importância de se desafiar, através delas, a distinção entre público e privado, por meio da qual se sustentam as concepções sobre a relação entre trabalho e gênero, entre trabalho doméstico e gênero e o equilíbrio entre trabalho e vida pessoal (Anzorena, 2008; Bruschini, 2006).

Cabe salientar por fim e justamente em relação à promoção de mudanças que, embora não fosse o objetivo central deste estudo, o método adotado não apenas possibilitou que suas participantes expressassem suas concepções sobre os papeis de gênero, como também possibilitou que tomassem consciência sobre os seus paradigmas pessoais, no sentido tomado por Fávero $(2007,2010,2012)$ e os analisasse crítica e coletivamente, sobretudo no que se refere aos papéis tradicionais femininos e masculinos, mostrando, mais uma vez, que os papéis de gênero guardam seus significados nas interações que pressupõem e que podem ser reelaborados. Essa análise crítica é imprescindível tanto para fundamentar novos significados para o processo de socialização, como também para fundamentar as políticas públicas voltadas para a igualdade de gênero, tal como discutido por Arnot (2006), Beetham e Demetriades (2007), Bruschini (2006), entre outras.

\section{Referências}

Abrão, L. G. M. (2009). A participação política da mulher: Uma análise do ponto de vista psicológico (Tese de doutorado não publicada). Instituto de Psicologia, Universidade de Brasília, Brasília, Brasil.

Anzorena, C. (2008). Estado y división de trabajo: Las reaciones de gênero em las nuevas condiciones del mercado laboral. Utopia e Práxis Latinomericana, 13(41), 47-68.

Algranti, L. M. (1993). Honradas e devotas: Mulheres da Colônia. Rio de Janeiro: José Olympio.

Arnot, M. (2006). Gender equality, pedagogy and citizenship. Affirmative and transformative approaches in UK. Theory and Research in Education, 2(4), 131-150.

Badinter, E. (1985). Um amor conquistado: O mito do amor materno (W. Dutra, trans.). Rio de Janeiro: Nova Fronteira. (Trabalho original publicado em 1980)

Barthes, R. (1977). Image, music, text (S. Health, trans.). New York: Hill \&Wang.

Beetham, G., \& Demetriades, J. (2007). Feminist research methodologies and development: Overview and practical application. Gender \& Development, 15(2), 199-216.

Bordini, G., \& Sperb, T. M. (2012). Concepções de gênero nas narrativas de adolescentes. Psicologia: Reflexão e Crítica, 25(4), 738-746.

Brody, L. R. (2000). The socialization of gender differences in emotional expression: Display rules, infant temperament, and differentiation. In A. H. Fischer (Org.), Gender and Emotion: Social Psychological Perspectives (pp. 24-47). United Kingdom: Cambridge University Press.

Bruner, J. (1991). The narrative construction of reality. Critical Inquiry, 1(18), 1-21.

Burns, A. (1999). Power between women: The constructed otherness of "other women". Feminism \& Psychology, 4(9), 410-413.

Bruschini, C. (2006). Trabalho doméstico: Inatividade econômica ou trabalho não remunerado? Revista Brasileira de Estudos de População, 2(23), 331-353. 
Câmara, S. G., \& Carlotto, M. S. (2007). Coping e gênero em adolescentes. Psicologia em Estudo, 12(1), 87-93. doi: 10.1590/ S1413-73722007000100011.

Chabrol, C., \& Bromberg, M. (1999). Préalables à une classification des actes de parole. Psychologie Française, 44(4), 291-306.

Chase, S. E. (2008). Narrative inquiry. Multiples lenses, approaches, voices. In N. K. Denzin \& Y. S. Lincoln (Eds.), Collecting and interpreting qualitative materials (pp. 57-94; $3^{\text {a }}$ Ed.). Los Angeles: SAGE Publications.

Chodorow, N. (1979). Estrutura familiar e personalidade feminina. In M.Z. Rosaldo \& L. Lamphère (Orgs.), A mulher, a cultura e a sociedade. (pp. 65-93). Rio de Janeiro: Paz e Terra.

Chodorow, N. (1999). The power of feelings: Personal meaning in psychoanalysis, gender, and culture. New Haven: Yale University Press.

Chodorow, N. (2002a). The cycle completed: Mother and children. Feminism \& Psychology, 1(12), 11-17.

Chodorow, N. (2002b). Response and afterword. Feminism \& Psychology, 1(12), 49-53.

Costa, F. G. (2006). A tomada de consciência e o grupo focal na transformação das representações sociais do envelhecimento: uma pesquisa de intervenção (Tese de doutorado não publicada). Instituto de Psicologia, Universidade de Brasília, Brasília, Brasil.

Del Priore, M. (1993) Ao sul do corpo: Condição feminina, maternidades e mentalidades no Brasil Colônia. Rio de Janeiro: José Olympio.

Fávero, M. H. (1999, Março). O conceito de felicidade na depressão: Relato de estudo de caso. Trabalho apresentado no VI Latini Dies e II Congresso Brasileiro de Psicoterapias Cognitivas, Rio de Janeiro. Retirado de www.fbtc.org.br/ Assets/Site/files/CBTC-II.pdf

Fávero, M. H. (2005). Desenvolvimento psicológico, mediação semiótica e representações sociais: por uma articulação teórica e metodológica. Psicologia: Teoria e Pesquisa, 21(1), 17-25.

Fávero, M. H. (2007). Paradigme personnel et champ conceptuel: Implications pour les situations didactiques. In M. Merri (Org.), Activité Humaine et Conceptualisation (pp. 625-634). Toulouse, France: Presses Universitaires du Mirail.

Fávero, M. H. (2010). Psicologia do gênero: Psicobiografia, sociocultura e transformações. Curitiba, PR: UFPR.

Fávero, M. H. (2012). A pesquisa de intervenção na construção de competências conceituais. Psicologia em Estudo, 1(17), 103-110.

Fávero, M. H. (2015). Subjetividade e objetividade na psicologia contemporânea: Apontamentos históricos, epistemológicos e filosóficos. Psicologia em Estudo, 20(2), 189-200.

Fávero, M. H., \& Abrão, L. G. M. (2006). "Malhando o gênero": O grupo focal e os atos da fala na interação de adolescentes com a telenovela. Psicologia. Teoria e Pesquisa, 22, 175-182.

Fávero, M. H., \& Abrão, L. G. M. (2012, Junho). Participação das mulheres na política brasileira: As representações sociais evocadas pelas suas vozes. Trabalho apresentado na $11^{\text {a }}$ Conferência Internacional sobre Representações Sociais - As Representações Sociais em Sociedades em Mudança, Évora, Portugal.

Fávero, M. H., \& Trajano, A. A. (1998). A leitura do adolescente: Mediação semiótica e compreensão textual. Psicologia: Teoria e Pesquisa, 14(3), 229-240.
Gergen, K. J. (1990). "If persons are texts". In S. B. Messer, L. A. Sass, \& R. L. Woolfolk (Eds.), Hermeneutics and Psychological Theory: Interpretative Perspectives on Personality, Psychotherapy and Psychopathology (pp. 28-50). New Brunswick: Rutger's University Press.

Gergen, K. J. (2001). Psychological science in a postmodern context. The American Psychologist, 56, 803-813.

Gergen, K. J. (2006). The relational self in historical context. International Journal for Dialogical Science, 1(1), 119-124.

Leaper, C. (2000). The social construction and socialization of gender during development. In P. H. Miller \& E. K. Scholnick (Eds.), Toward a feminist developmental psychology (pp. 127152). London: Routledge.

Lotman, Y. M. (1988). The semiotics of culture and the concept of a text. Soviet Psychology, 3(XXV), 52-58.

Lotman, Y. M. (1990). Universe of the mind. A Semiotic Theory of Culture (A. Shukman, trans.). Bloomington: Indiana University Press.

Mehta, C. M., \& Strough, J. (2010). Gender segregation and gendertyping in adolescence. Sex Roles, 63, 251-263. doi 10.1007/ s11199-010-9780-8.

Morawiski, J. G. (1997). The science behind feminist research methods. Journal of Social Issues, 4(53), 667-681.

Morawiski, J. G. (2005). Reflexivity and the psychologist. History of the Human Science, 18(4), 77-105.

Oliveira Vieira, D. (2008). A tomada de consciência no desenvolvimento de competencias conceituais em professoras: uma pesquisa de intervenção com foco no autismo (Tese de doutorado não publicada). Instituto de Psicologia, Universidade de Brasília, Brasília, Brasil.

Perrot, M. (1998). Les femmes ou les silences de l'histoire. Paris: Flammarion.

Pichevin, M.-F., \& Hurtig, M. C. (2007). On the necessity of distinguishing between sex and gender. Feminism \& Psychology, 17(4), 447-452.

Rial, C., Souza Lago, M. C. de, \& Grossi, M. P. (2005). Relações sociais de sexo e relações de gênero: Entrevista com Michèle Ferrand. Estudos Feministas, 13(3), 677-689.

Ricoeur, P. (1991). "Life in quest of narrative". In D. Wood (Ed.), On Paul Ricoeur: Narrative and Interpretation (pp. 20-33). Routledge: London.

Richards, G. (2002). The psychology of psychology. A history grounded sketch. Theory \& Psychology, 12(1), 7-36.

Riger, S. (1992). Epistemological debates, feminist voices. Science, social values, and the study of women. American Psychologist, 6(47), 730-740.

Robinson, K. H. (2012). 'Difficult citizenship': The precarious relationships between childhood, sexuality and access to knowledge. Sexualities, 15(3/4), 257-276.

Rocha-Coutinho, M. L. (1994). Tecendo por trás dos panos: A mulher brasileira nas relações familiares. Rio de Janeiro: Rocco.

Rosistolato, R. P. (2009). Gênero e cotidiano escolar: Dilemas e perspectivas da intervenção escolar na socialização afetivosexual dos adolescentes. Estudos Feministas, 17(1), 11-30.

Rutherford, A. (2011). From the ground up: Feminist approaches, methods, and critiques. Psychology of Women Quarterly, 35(1), 175-179.

Scott, J. W. (1988). Gender and the politics of history. New York: Columbia University Press. 
Smedslund, J. (2009). The mismatch between current research methods and the nature of psychological phenomena. Theory \& Psychology, 19(6), 778-794.

Smedslund, J. (2012). What follows from what we all know about human beings. Theory \& Psychology, 22(5), 658-668.

Smith, R. (2005). Does reflexivity separate the human sciences from the natural sciences? History of the Human Sciences, 18(1), 01-25.

Tian, W., Jimarkon, P., \& Singhasiri, W. (2011). Designing a transcription system for face-to-face PhD Supervisory. Doing Research in Applied Linguistics. Recuperado de http://arts.kmutt.ac.th/dral/PDF\%20CD\%20on\%20Web/108119_Designing_a_Transcription_System_for_Face-to-face.pdf West, C., \& Zimmerman, D. H. (1987). Doing gender. Gender and Society, 1, 125-151.
Unger, R. K. (1979). Toward a redefinition of sex and gender. American Psychologist, 11(34), 1085-1094.

Unger, R. K. (1981). Sex as a social reality: Field and laboratory research. Psychology of Women Quarterly, 5, 645-653.

Vespa, J. (2009) Gender ideology construction: A life course and intersectional approach. Gender \& Society, 3(23), 363-387.

Vion, R. (2000). La communication verbale. Analyse des interactions. Paris: Hachette Livre.

Recebido em 23.05.2014

Primeira decisão editorial em 05.10.2015

Versão final em 18.10.2015

Aceito em 26.11.2015

\section{REPRODUÇÃO DOS DOIS PRIMEIROS SLIDES PROJETADOS DURANTE A $3^{\text {a }}$ FASE DO ESTUDO.}

SLIDE 1

VOCÊS ACEITARAM PARTICIPAR DESTE ESTUDO E ESTIVERAM LIDANDO COM A NARRATIVA DE SUAS VIDAS, EM DUAS OCASIÕES:

- NA PRIMEIRA ESCREVERAM UM TEXTO.

- NA SEGUNDA RESPONDERAM A QUESTÕES SUSCITADAS PELO TEXTO QUE ESCREVERAM.

HOJE CONVIDAMOS VOCÊS A DISCUTIREM JUNTAS: 1/ O QUE ESTES DOIS MOMENTOS FOCADOS NAS SUAS VIDAS, LEVARAM VOCÊS A PENSAR, REFLETIR, SENTIR.

\section{SLIDE 2}

NAS SUAS NARRATIVAS ENCONTRAMOS PONTOS COMUNS COMO POR EXEMPLO:

A REFERÊNCIA À AUSÊNCIA DO PAI;

- A REFERENNCIA À AUSÊNCIA DO PAI DOS SEUS FILHOS.

2/ CONVIDAMOS VOCÊS A DISCUTIREM ESTES DOIS PONTOS 